\title{
A DIVERSIDADE CULTURAL DA EJA: O PAPEL DA ESCOLA NA PROMOÇÃO DE UMA EDUCAÇÃO VOLTADA AO TRATAMENTO DAS IDENTIDADES PESSOAIS, SOCIAIS E CULTURAIS ${ }^{1}$
}

\author{
Tomaz Caetano Dutra ${ }^{2}$, EEM AFAD \\ tomaz.caetano@bol.com.br
}

\author{
Maria Adriana Leite Alves ${ }^{3}$, EEM AFAD \\ adriana_lavras@outlook.com
}

\begin{abstract}
RESUMO
Buscamos evidenciar, através deste artigo, as particularidades que envolvem a Educação de Jovens e Adultos (EJA), tendo como objetivo geral, realizar uma reflexão sobre a prática do ensino desempenhado em turmas de EJAs, na possibilidade de adaptar um modelo educativo que inclua o aluno como norte das propostas de ensino que se consumarão no decorrer do ano letivo. A inclusão deverá basear-se nas identidades em que alunos são percebidos, seja na questão social, econômica, etária, de gênero, cultural e etc. O professor juntamente com a instituição escolar, deverá garantir um espaço acolhedor e flexível no que se refere ao desempenho das obrigações domésticas, ou de trabalho, que os alunos por ventura poderão dispor, respeitando as regras de cada instituição.
\end{abstract}

PALAVRAS-CHAVE: EJA; DIVERSIDADE; CULTURA.

\section{ABSTRACT}

Through this article, we seek to highlight the particularities that involve the Education of Young and Adults (EJA), with the general objective of reflecting on the practice of teaching in EJA classes, on the possibility of adapting an educational model that includes the Student as the north of the teaching proposals that will be consummated during the school year. Inclusion should be based on the identities in which students are perceived, whether in the social, economic, age, gender, cultural, and so on. The teacher together with the school institution should guarantee a welcoming and flexible space regarding the performance of the

\footnotetext{
${ }^{1} \mathrm{O}$ presente trabalho (não) contou com apoio financeiro de nenhuma natureza para sua realização

${ }^{2}$ Professor efetivo da rede estadual do Ceará, na cidade de Lavras da Mangabeira. Especialista em História do Brasil (2013) - FIP -(Faculdades Integradas de Patos)

${ }^{3}$ Professora efetiva da rede estadual do Ceará, na cidade de Lavras da Mangabeira. Mestre em Letras pelo Programa de Pós-Graduação em Letras (PROFLETRAS) - UFCG - Universidade Federal de Campina Grande - Campus Cajazeiras-PB (2016)
} 
domestic or work obligations that students may have available, respecting the rules of each institution.

KEYWORDS: EJA; DIVERSITY; CULTURE.

\section{RESUMEN}

Se buscan evidenciar, a través de este artículo, las particularidades que envuelven la Educación de Jóvenes y Adultos (EJA), teniendo como objetivo general, realizar una reflexión sobre la práctica de la enseñanza desempeñada en las clases de EJAs, en la posibilidad de adaptar un modelo educativo que incluya Al alumno como norte de las propuestas de enseñanza que se consumarán a lo largo del año escolar. La inclusión deberá basarse en las identidades en que los alumnos son percibidos, ya sea en la cuestión social, económica, de edad, de género, cultural, etc. El profesor junto con la institución escolar, deberá garantizar un espacio acogedor y flexible en lo que se refiere al desempeño de las obligaciones domésticas, o de trabajo, que los alumnos por ventura podrán disponer, respetando las reglas de cada institución.

PALABRAS CLAVE: EJA; DIVERSIDAD; CULTURA.

\section{INTRODUÇÃO}

A Educação de Jovens e Adultos (EJA) é vista no panorama educacional atual por dois vieses, o primeiro como educação "especial" para aqueles que estão fora de faixa idade/série, e dessa forma há um olhar de exclusão; o segundo é o do recomeço, da segunda chance, de oportunizar jovens e adultos a concluírem a Educação Básica. Assim, para que não haja este e outros tipos de estereótipos, devemos compreender a qualificação educacional nas escolas onde funciona esta modalidade de ensino a partir de um panorama desfavorável do entendimento básico de seu funcionamento.

Educar jovens e adultos para a vida é um desafio. Repensar quais são os objetivos, as metas, os enfoques, as epistemologias, as teorias que fundamentam a docência não é uma tarefa fácil, mas necessária. Precisa-se transformar a educação para transformar a realidade recursivamente, tornando a recíproca verdadeira. (TEIXEIRA, 2006, p. 192)

No tocante a colocação textual de Teixeira (2006), o nível de ensino onde se encontra a EJA, difere das salas em que estão inscritos os alunos regulares e tradicionais da instituição, 
a própria proposta pedagógica e curricular da EJA possibilita uma determinada desvalorização educacional se percebida frente às outras modalidades de ensino.

Por vezes visualiza-se a EJA a partir de um padrão inferior, onde não se procura resultados esplêndidos ou favoráveis ao processo de ensino-aprendizagem, procura-se apenas qualificar determinados alunos com faixas etárias divergentes, padrões culturais distintos e camadas sociais desiguais em um nível mínimo de saber, transparecendo um objetivo educacional que não possui um fim no aluno, mas, sim no modelo educacional onde o mesmo se encontra inserido.

Define-se, portanto, um estudo que englobe um saber-fazer por parte dos docentes e discentes, e que os mesmos consigam se adequar a uma estratégia de ensino que reforce uma maior aquisição do conhecimento. Analisando uma maior aproximação do professor, juntamente a uma proposta mais democrática do saber, possui-se um terreno fértil e propício para que o processo de ensino-aprendizagem ocorra com naturalidade e equidade, respeitando a individualidade de todos que se educam em sala de aula, pois de acordo com Paulo Freire:

O fundamental é que professor e alunos saibam que a postura deles, do professor e dos alunos, é dialógica, aberta, curiosa, indagadora e não apassivada, enquanto fala ou enquanto ouve. O que importa é que professor e alunos se assumam epistemologicamente curiosos. Neste sentido, o bom professor é o que consegue, enquanto fala, trazer o aluno até a intimidade do movimento de seu pensamento. Sua aula é assim um desafio e não uma "cantiga de ninar". Seus alunos cansam, não dormem. Cansam porque acompanham as idas e vindas de seu pensamento, surpreendem suas pausas, suas dúvidas, suas incertezas. (FREIRE, 1996, p. 96)

Deve-se repensar todo esse conceito ou preconceito em que a EJA está envolta e encarar uma nova forma de se trabalhar nesta modalidade de ensino, por meio de uma valorização de seus atributos culturais. Destacando-se os significados que cada aluno carrega consigo e orquestrando suas pessoalidades e individualidades a um plano de ensino inovador, que procure um fim no aluno, e que o mesmo consiga se enxergar como um agente histórico, pertencente ao meio em que vive, e atuante nas esferas públicas como um cidadão educado e capaz.

\section{DIALOGANDO SOBRE A PROBLEMÁTICA DE EXCLUSÃO DA EJA}


A proposta de se produzir uma pesquisa com enfoque na diversidade cultural da Educação de Jovens e Adultos, reafirma uma preocupação inerente a pesquisadores, historiadores e pedagogos que compreendem a realidade de uma educação que está caminhando (mesmo que a passos lentos) em seu aperfeiçoamento desejável em termos governamentais. Contudo, para compreender o problema em questão, procura-se investigar assim as raízes desses problemas, que podem ser destacados na globalização de uma economia capitalista, que capacita uma massificação cultural homogeneizante, buscando reforçar um tecnicismo para aqueles que se encontram deslocados em seus níveis educacionais.

Assim, menosprezados por uma elite intelectual e econômica, essa camada da sociedade que não compartilha das mesmas benesses educacionais, está marginalizada no que se refere às decisões políticas, ou nas participações em lutas sociais por não compreenderem suas possibilidades como cidadãos sabedores de seus direitos e deveres.

A EJA se encontra assim, num padrão de ensino que possui uma missão de abrigar esses jovens e adultos marginalizados na sociedade, com todos os problemas que cada ser humano, com um mínimo de responsabilidade carrega consigo. Enfatizando todo um histórico de evasão escolar, dificuldades na aprendizagem, exclusão social e no desempenho escolar rudimentar durante todo o período de estudo desenvolvido por esses estudantes.

As questões da diversidade cultural se colocam especificamente no país, pelo número crescente e cada vez mais diversificado de alunos de diferentes condições sociais, diversas etnias, visível especificamente, a partir da obrigatoriedade e universalização da escola. (SOUZA, 2001, p. 119)

A partir do paradigma apresentado, sobrepõe-se que a humanização do saber, consiga assim direcionar um caminho mais confiável ante os obstáculos que se apresentam, na trajetória escolar de um aluno da EJA. Pois se o Estado tem o dever de garantir uma educação gratuita a todos, deve também, procurar garantir a permanência do aluno, mesmo que este se mostre desmotivado ou incrédulo frente ao cotidiano escolar. A partir de estratégias que ambicionem assim "resignificar" o aluno e a sua participação no processo de ensinoaprendizagem. 
Sendo assim, deve-se estudar a diversidade cultural da EJA, assim como definir o papel da escola e do professor nos tratamentos pessoais, coletivos e culturais dos alunos, sendo relevante para a compreensão do nosso processo educacional contemporâneo.

Dessa forma, pesquisadores/professores e devem passar a ter uma visão e mostra-la para a sociedade de que a EJA tem o seu papel revolucionário, pois possibilita uma maior integração àqueles que se encontravam, deslocados do sistema educacional, além de reforçar o conceito de educação para todos, destaca-se assim o papel do estado na integração e permanência dos alunos da EJA previstos em lei:

Art. 37. A educação de jovens e adultos será destinada àqueles que não tiveram acesso ou continuidade de estudos no ensino fundamental e médio na idade própria.

$\S 1^{\circ}$. Os sistemas de ensino assegurarão gratuitamente aos jovens e aos adultos, que não puderam efetuar os estudos na idade regular, oportunidades educacionais apropriadas, consideradas as características do alunado, seus interesses, condições de vida e de trabalho, mediante cursos e exames.

$\S 2^{\circ}$. O Poder Público viabilizará e estimulará o acesso e a permanência do trabalhador na escola, mediante ações integradas e complementares entre si. (LDB, 2015, p. 27)

No tocante a diversidade cultural dos alunos da EJA, compõe-se um quadro que dificilmente fora explorado como uma alternativa estratégica de permanência do aluno, aos níveis de composição no quadro discente, objetivados pelo governo. Já que os níveis de reprovação e evasão que se encontram a modalidade de ensino da EJA são os maiores do que em qualquer outra modalidade educacional da educação básica. No total, 3,4 milhões de adultos frequentavam a escola em 2015, número 4,5\% menor que em 2014. A queda já vinha ocorrendo desde 2007, segundo os dados divulgados pelo MEC (TOKARNIA, 2016).

Reafirma-se assim uma necessidade de visualizar por uma ótica flexível, um modelo de ensino na EJA, e que procure assim, adequar um sentido educacional ao aluno no tocante as suas funções na escola. Encara-se assim o aluno como um dos protagonistas do saber, valorizá-lo nas suas mais distintas características e utilizar as individualidades de cada um como uma estratégia da permanência do aluno na escola. Como é percebido por Luckesi (2001) apud Patrícia Mendes et al (2009) quando o mesmo enfatiza que "Estar interessado que o aluno aprenda e se desenvolva individual e coletivamente", pois, a valorização do 
discente por parte do docente, determina um significado especial na aquisição de saber e no processo de ensino-aprendizagem aos alunos pertencentes a modalidade da EJA.

O papel da escola consiste a partir deste modelo inovador, viabilizar condições propícias para o aprendizado, fornecer incentivo e adequações para a atuação de professores e alunos, e assim, que o professor consiga utilizar esse ambiente para poder assim, desenvolver aulas atrativas com base na diversidade cultural, e nas identidades particulares que cada um carrega consigo. Como avalia a pedagoga Patrícia Mendes et al (2009, p. 6)

Em EJA, destacadamente, deve-se dar valor à "aprendizagem histórica", uma vez que os alunos que ela acorre, em destaque aos adultos analfabetos, sem desconsiderar os jovens, trazem a sua história de vida que se configura como o resultado das experiências que acumularam em suas vidas. E é dessas aprendizagens históricas que o professor, ao contextualizá-las, deve partir para um ensino no qual o conteúdo deve estar impregnado de significância, em possibilidade de aplicação desses conhecimentos no cotidiano, num processo de interesses entre o conhecimento empírico e escolar (científico).

A contribuição da pesquisa ofertada permite-nos tecer uma formulação educacional, no sentido de proporcionar uma melhor forma de educar, avaliar e ensinar aos alunos da EJA. Destacando assim, um contexto positivo de encarar as dificuldades prescritas nesta modalidade de ensino, por uma alternativa dialógica e pluriculturalista, em acordo com os PCN's e seguindo a LDB como um guia de atuação docente.

\section{A IMPORTÂNCIA DO TRABALHO DIRECIONADO À EJA}

A relevância da pesquisa em questão, consiste em uma melhor visualização das estratégias que podem ser desempenhadas, em escolas que adotem a EJA como modalidade de ensino. Resguardando um compromisso com a melhoria dos resultados individuais e coletivos dos alunos. Vincula-se concomitantemente a um objetivo na melhoria educacional de nossa nação, baseado na premissa freireana, de uma "educação libertadora", que consiga metamorfosear o ser humano a um patamar mais evoluído, que consiga assim transparecer uma maior humanização nas plenitudes funcionais de um cidadão mais democrático e consciente dos direitos e deveres presentes em suas aptidões. 
Respeitar a diversidade cultural da EJA significa assim, remontá-la a outro nível de atuação. É romper com o tradicionalismo da adaptação mais lenta do modelo que se encontra presente em outros níveis de ensino, e na existência da "ditadura do saber" que tem com alvo o professor, embutido num papel de "ditador do conhecimento".

A diversidade cultural se mostra mais favorável na condição de uma maior permanência em sala de aula, já que proporcionará um maior vínculo com as aulas ministradas pelo professor, garantindo assim um melhor indicador positivo nos índices aprovativos e de permanência na escola.

A pesquisa em questão, intitulada "A diversidade cultural da EJA: O papel da escola na promoção de uma educação voltada ao tratamento das identidades pessoais, sociais e culturais". Insere-se na linha de pesquisa: Práticas educativas, culturas e diversidades. Tendo como objetivo geral, realizar uma reflexão sobre a prática do ensino desempenhado em turmas de EJAs, na possibilidade de adaptar um modelo educativo que inclua o aluno como norte das propostas de ensino que se consumarão no decorrer do ano letivo. A inclusão deverá basear-se nas identidades em que alunos são percebidos, seja na questão social, econômica, etária, de gênero, cultural e etc.

O professor juntamente com a instituição escolar, deverá garantir um espaço acolhedor e flexível no que se refere a desempenho das obrigações domésticas, ou de trabalho, que os alunos por ventura poderão dispor, respeitando as regras de cada instituição.

A função de uma educação de teor cultural e dialógica, fornece uma ação interdisciplinar que deve ser executada em todas as disciplinas que ministrarão aulas na EJA, a promoção cultural assim respeitará o indivíduo em sua individualidade e procurará por meio da realidade em que o mesmo se insere (em suas características mais diversas), elaborar um plano de aula que se adapte a natureza social, política e cultural do aluno, favorecendo uma maior comunicação no trabalho docente e em sua atuação no interior da sala de aula.

Além de ajustar o saber científico aos saberes prévios dos alunos, o professor se torna mais apto ao oferecer uma condição avaliativa mais coerente com a situação educacional, que está vigente aos alunos de EJAs (deslocados, excluídos e marginalizados), onde os mesmos não dispõem dos mesmos recursos de aprendizagem fornecidos em outras modalidades de ensino. Destacando o combate ao preconceito e revalidando um maior compromisso perante a aprendizagem do aluno, já que o mesmo pode ser diagnosticado como um elemento humano 
essencial na efetuação de qualquer trabalho na escola, e onde todos os esforços devem ser direcionados.

\section{METODOLOGIA}

A metodologia enfatizada no trabalho proposto possui um caráter predominantemente qualitativo, de teor crítico e de aspecto inovador. Desenvolvendo assim uma pesquisa por meio da observação teórica, levando em consideração as características do objeto a ser investigado (no caso a EJA, na compreensão de suas múltiplas possibilidades, mas, também nos inúmeros problemas que se encontram presentes neste modelo de ensino).

Busca-se analisar relatos orais por meio de entrevistas (alunos, pais, professores, coordenadores, gestores, comunidade escolar e etc.) que possam influir na agregação de conhecimento, e no aumento dos inúmeros questionamentos que possam ser indagados aqui, na possibilidade de problematizar de uma maneira significativa o tema em questão.

Procuram-se utilizar estratégias de observação na pesquisa de campo (na instituição escolar), que possibilitem um estudo das atitudes e pensamentos do educando, acrescentando, aportes teóricos que adicionem experiências significativas no conhecimento exigido pela proposta pedagógica da pesquisa.

Os materiais de apoio apresentados fornecerão um maior recurso teórico para uma discussão que englobe pensamentos determinantes ao tema pesquisado, para poder determinar, uma avaliação com maior precisão ao sistema educacional, uma maior compreensão a relação docente-discente, no processo de ensino-aprendizagem e no papel da escola na educação dos alunos.

Investigam-se na pesquisa em questão, livros, documentários, notícias de artigos de jornais e revistas, fotos de época, gráficos, biografias e etc. Dentre as bibliografias utilizadas, alguns autores se mostram essenciais para uma compreensão mais nítida e de uma maior completude, assim como de um caráter relativamente minucioso ao tema estudado como: Paulo Freire, Augusto Niche, Cipriano Luckesi, Álvaro Vieira entre outros.

Remontando assim maior aporte teórico, e uma discussão mais intelectualizada em relação às perspectivas educacionais em jogo. Envolvendo a ética, avaliação e relação 
professor-aluno. Determinando uma maior sensibilização ao tema, nos ajudando a sentir um pouco mais responsáveis, por uma educação que tem como sua mais favorável característica o sentimento de solidariedade e coletividade que devem ser partilhadas por todos brasileiros, pois com dizia Paulo Freire (1987, p. 39): "Ninguém educa ninguém, ninguém educa a si mesmo, os homens se educam entre si, mediatizados pelo mundo", sem medir seu gênero, classe econômica, status social, cultura ou religião.

\section{CONSIDERAÇÕES FINAIS}

Dessa forma estamos propondo um maior estudo de caso sobre a EJA, que esta modalidade de ensino receba um olhar diferenciado, não o olhar preconceituoso que marginaliza e desdenha, mas o olhar otimista, o da verdadeira inclusão social, que faça jus a verdadeira Educação de Jovens e Adultos.

Aqui se propõe, a execução e a adaptação partem de cada necessidade, de cada grupo.

\section{6 - REFERÊNCIAS}

BRASIL. LDB: Lei de Diretrizes e Bases da Educação Nacional. 11. ed. Brasilia: Centro de Documentação e Informação: edições Câmara, 2015.

Disponível em <http://www.ufsj.edu.br/portal2-repositorio/File/proen/ldb_11ed.pdf> Acesso em: 22 mar. 2017.

FREIRE, Paulo. Pedagogia da autonomia: saberes necessários à prática educativa. 23. ed. São Paulo: Paz e Terra, 1996.

Pedagogia do Oprimido. 17.ed. Rio de Janeiro: Paz e Terra, 1987.

LUCKESI, Cipriano. Avaliação da Aprendizagem Escolar. São Paulo: Cortez, 2001.

TEIXEIRA, Augusto Niche. Educação frente à complexidade educando jovens e adultos para a vida. In: SHEIBEL, Maria Fani e LEHENBAUER, Silvana (orgs.). Reflexões sobre a Educação de Jovens e Adultos. Porto Alegre: PALLOTI, 2006.

RODRIGUES, Patrícia Mendes et al. Práticas cotidianas na docência dos professores do Ensino Médio na EJA: reflexões sobre o processo de legitimação dos saberes. X Salão de Iniciação Científica: PUCRS, 2009 
SOUZA, Maria Antônia. Educação de Jovens e Adultos. Curitiba: Ibepx, 2007

TOKARNIA, Mariana. Disponível em:

<http://agenciabrasil.ebc.com.br/educacao/noticia/2016-03/censo-escolar-3-milhoes-de alunos-entre-4-e-17-anos-estao-fora-da-escola> Acesso em: 22 mar. 2017. 